\title{
Crescimento e ciclo de produção de mudas de Eucalyptus em recipientes
}

\author{
Teresa Aparecida Soares de Freitas ${ }^{1}$, Mariana Duarte Silva Fonseca² ${ }^{2}$, Sandra Selma Marques de Souza ${ }^{1}$, Thâmara Moura Lima', \\ Andrea Vita Reis Mendonça ${ }^{1}$, Aline Pinto dos Santos ${ }^{1}$ \\ ${ }^{1}$ Universidade Federal do Recôncavo da Bahia, Rua Rui Barbosa, n 710, Centro, CEP 44.380-000, Cruz das Almas, BA, Brasil \\ ${ }^{2}$ Universidade Federal do Espírito Santo, Av. Fernando Ferrari, n 514 , Goiabeiras, CEP 29075-910, Vitória, ES, Brasil
}

*Autor correspondente:
tas_freitas@hotmail.com

Termos para indexação:

Eucalyptus

Tubetes

Desempenho

Index terms:

Eucalyptus

Seedling containers

Performance

Histórico do artigo:

Recebido em 15/08/2013

Aprovado em 25/11/2013

Publicado em 31/12/2013

doi: 10.4336/2013.pfb.33.76.575
Resumo - Com objetivo de estudar o comportamento de mudas de três espécies de eucalipto produzidas em dois tamanhos de recipientes, foram instalados dois experimentos no viveiro florestal da Universidade Federal do Recôncavo da Bahia, campus Cruz das Almas, ambos em Delineamento Inteiramente Casualizado, esquema fatorial 3 x 2, (três espécies e dois tamanhos de tubetes), com 4 repetições. O primeiro experimento foi referente a produção das mundas no viveiro e o segundo consistiu na simulação de campo. As características avaliadas foram: altura, diâmetro, área foliar, número de folhas, massa seca da parte aérea, massa seca do sistema radicular e percentagem de deformação de raízes. As mudas de todas as espécies produzidas em tubetes de $180 \mathrm{~cm}^{3}$ apresentaram maior crescimento para todas as variáveis avaliadas, podendo ser levadas para o campo mais cedo, diminuindo o seu ciclo de produção no viveiro. Nos tubetes de maior volume $\left(180 \mathrm{~cm}^{3}\right)$ as mudas ficam aptas para o plantio aos 60 dias, enquanto as provenientes de tubetes de menor volume $\left(55 \mathrm{~cm}^{3}\right)$ atingem o padrão mínimo exigido para o plantio no campo aos 120 dias. No experimento de simulação de campo foi verificado que mudas produzidas em tubetes de $55 \mathrm{~cm}^{3}$ apresentaram menor crescimento em altura e diâmetro, menor massa seca da parte aérea e raiz e maior número de deformações de raízes, independente da espécie avaliada.

\section{Growth and seedling production cycle of Eucalyptus in containers of two different sizes}

\begin{abstract}
Aiming to study the behavior of seedlings of three eucalypt species produced in two sizes of containers and to verify their performance after two months of planting, two experiments were established at the forest nursery, Universidade Federal do Recôncavo da Bahia, campus Cruz das Almas, both of in a completely randomized design, factorial $3 \times 2$ (three species and two containers sizes), with 4 replicates. The first experiment was referring to production of seedlings in the nursery and the second consisted of the field simulation. The characteristics evaluated were: height, diameter, leaf area, leaf number, shoot dry weight, root dry weight and percentage of deformed roots. The seedlings of all species produced in containers of $180 \mathrm{~cm}^{3}$ showed higher growth for all variables, which can be taken to the field earlier, reducing its production cycle in the nursery. In containers of larger volume $\left(180 \mathrm{~cm}^{3}\right)$ the seedlings are ready to be planted at 60 days, while those from containers at lower volume $\left(55 \mathrm{~cm}^{3}\right)$ reach the minimum standard required for planting in the field at 120 days. In simulation experiment in the field it was observed that seedlings grown in containers of $55 \mathrm{~cm}^{3}$ showed less growth in height and diameter, lower dry mass of shoots and roots and more deformed roots, independent of the species evaluated.
\end{abstract}




\section{Introdução}

Os recipientes mais utilizados em produção de mudas de eucalipto são os tubetes de $55 \mathrm{~cm}^{3}$, que possuem estrias internas que conduzem as raízes, impedindo seu enovelamento, situação frequente quando se utiliza o saco plástico. Entretanto, embalagens com limitada capacidade volumétrica apresentam a desvantagem de causar outras deformações radiculares, tais como a dobra e o estrangulamento das raizes, comprometendo o desenvolvimento das mudas no campo. Pesquisadores têm relatado a incidência de deformações radiculares produzidas pelo sistema de tubetes de $55 \mathrm{~cm}^{3}$ para eucaliptos, comparados a outros tipos de recipientes (Barroso et al., 2000a; Freitas et al., 2005; Freitas et al., 2009; Leles et al., 2001; Lopes, 2005), em função do reduzido volume de substrato.

Segundo Gomes \& Paiva (2006), a qualidade e os custos da produção de mudas estão diretamente relacionados ao tipo de recipiente e seus respectivos volumes que, consequentemente, interferem na quantidade de água e nutrientes ofertados às plantas e na arquitetura do sistema radicular. A vantagem de utilização de tubetes de menor volume é a maior produtividade e menor custo de produção de mudas, porém recipientes de maiores dimensões tendem a resultar em melhor desenvolvimento das mudas (Viana et al., 2008). Ao aumentar o tamanho do recipiente, também aumenta a demanda de insumos, o espaço no viveiro, a necessidade de mão de obra e o custo de transporte, reduzindo o rendimento no plantio (Cunha et al., 2005; Ferraz \& Engel, 2011). Por outro lado, tubetes de maiores volumes reduzem o desperdício de água no processo de irrigação e produzem mudas mais desenvolvidas. A produção de mudas mais robustas poderá acelerar o crescimento inicial, reduzir a intensidade de tratos culturais no campo, principalmente a capina, e diminuir o ciclo de produção. Considerando a responsabilidade com o uso da água, a elevada demanda por produtos madeireiros e o avanço de plantios florestais em áreas com restrições hídricas acentuadas, justifica-se avaliar a utilização de tubetes de maiores dimensões para produção de mudas de eucalipto.

Dentre as espécies denominadas popularmente como eucaliptos, Corymbia citriodora e Eucalyptus robusta estão entre as espécies mais utilizadas no mundo (Mora \& Garcia, 2000), enquanto que Eucalyptus urophylla está entre as mais plantadas do Brasil (Scanavaca Junior \& Garcia, 2003). C. citriodora, que pertencia anteriormente ao gênero Eucalyptus, apresenta grande destaque na produção de óleos essenciais, sendo amplamente cultivada nas regiões sudeste e nordeste, além de sua madeira ter múltiplos usos (Reiff, 2009). E. urophylla apresenta grande potencial para as regiões Norte e Nordeste, onde os plantios florestais estão se expandindo (Scanavaca Junior \& Garcia, 2003), além de possuir elevada resistência ao cancro do eucalipto (Mora \& Garcia, 2000), sendo utilizada em programas de melhoramento genético para a formação dos híbridos denominados urograndis (Higa \& Higa, 2000). A espécie E. robusta apresenta tolerância à salinidade, podendo ser cultivada em ambientes cujo solo tenha salinidade como fator limitante ao desenvolvimento de outras espécies (Mendonça et al., 2010).

O objetivo desse trabalho foi avaliar o crescimento de mudas de três espécies de eucalipto produzidas em dois tamanhos de recipientes, além de verificar seu desempenho após dois meses de plantio.

\section{Material e métodos}

O trabalho foi realizado no viveiro florestal da Universidade Federal do Recôncavo da Bahia, Campus Cruz das Almas. O Município situa-se a 1240’12” S e 3906'07' W (Superintendência de Estudos Econômicos de Sociais da Bahia, 2010), apresenta clima tropical quente e úmido, com pluviosidade média anual de 1200 mm, temperatura anual média de $24,5{ }^{\circ} \mathrm{C}$, umidade relativa média do ar de $80 \%$, estando a $220 \mathrm{~m}$ de altitude (Lessa et al., 2009). O experimento foi conduzido em delineamento inteiramente casualizado em esquema fatorial 3 x 2, com três espécies (Eucalyptus urophylla, Eucalyptus robusta e Corymbia citriodora) e dois tamanhos de tubetes $\left(55\right.$ e $\left.180 \mathrm{~cm}^{3}\right)$, com 4 repetições e 49 mudas por repetição, sob sombrite $30 \%$ e com telado plástico. Utilizou-se o substrato comercial Vivato Slim ${ }^{\circledR}$, suplementado com $6,52 \mathrm{~g} \mathrm{Kg}^{-1}$ de substrato do fertilizante Osmocote ${ }^{\circledR}$ (19-09-12).

As bandejas foram dispostas em bancadas de madeira e as mudas irrigadas manualmente, duas vezes ao dia, até a saturação do substrato, observada pelo gotejamento proveniente da abertura terminal do tubete. Quando $80 \%$ dos tubetes apresentaram plântulas, 10 dias após a semeadura, procedeu-se a repicagem e raleio, deixando apenas a mais central e vigorosa. Dois meses após a semeadura as mudas foram colocadas a pleno sol em bancadas. 
As avaliações de altura e diâmetro foram realizadas aos 30, 45, 60, 75, 90, 105 e 120 dias após a semeadura. A altura foi obtida com auxilio de uma régua graduada (em centímetros) e o diâmetro com paquímetro digital (em milímetros).

Aos 120 dias foram tomadas quatro mudas por parcela para avaliação da área foliar, número de folhas, massa seca da parte aérea, massa seca do sistema radicular e percentagem de deformação de raízes.

A área foliar foi avaliada por meio do medidor de área foliar com o software WinDIAS 3 - Leaf Image Analysis System (Delta-T Devices Ltd.), e em seguida a parte aérea foi seca em estufa a $65^{\circ} \mathrm{C}$ por um período de $72 \mathrm{~h}$ para quantificação da massa seca da parte aérea.

Para obtenção da percentagem de deformação, as raízes das mudas foram lavadas em água corrente utilizando peneiras para evitar ao máximo a perda de raízes, e após a lavagem foram quantificados o número de raízes emitidas e o número de deformações nas raízes. Através desses valores foi determinada a percentagem de deformação do sistema radicular das mudas. Consideraram-se como deformação as dobras, espiralamentos (enovelamentos) e estrangulamentos (Carneiro, 1995).

Após a determinação do número de raízes emitidas e do número de deformações nas raízes, estas foram levadas para estufa para obtenção da massa seca do sistema radicular, como realizado para a parte aérea.

Ao final do ciclo de produção das mudas (120 dias após a semeadura), com o objetivo de verificar o desempenho pós-plantio das três espécies de eucalipto produzidas nos dois tamanhos de tubetes, quatro mudas de cada repetição foram transplantadas para sacolas de 11 Litros (30 cm de altura), preenchidas com subsolo de Latossolo Amarelo adubado com NPK 04-14-08 na proporção de $6 \mathrm{Kg} \mathrm{m}^{-3}$ de solo. No momento do transplantio e após dois meses as mudas foram avaliadas quanto à sua altura e diâmetro do colo. Avaliaram-se também a massa seca da parte aérea e raiz, e quantificação das deformações radiculares, conforme metodologia descrita anteriormente.

Os dados foram submetidos à análise de variância $(\alpha=0,05)$. Para os fatores quantitativos foram ajustadas equações de regressão pelo método de regressão sequencial, sendo observada a distribuição gráfica dos resíduos. Para os fatores qualitativos aplicou-se o teste de Tukey $(\alpha=0,05)$ para comparação de médias. Os dados de incremento na fase de produção de mudas foram submetidos a análise de variância segundo parcelas subdivididas no tempo, conforme Dias \& Barros (2009). Antes de submetidos à análise de variância, os dados foram analisados quanto à homogeneidade pelo teste de Cochran e normalidade de resíduos pelo teste de Lilliefors.

\section{Resultados e discussão}

Os fatores, tamanho do tubete e espécie, atuaram independentemente nas variáveis altura $(\mathrm{H})$, diâmetro (D), área foliar (AF) e massa seca do sistema radicular (MSSR), sendo que todas estas variáveis responderam ao tamanho de tubetes (Tabela 1) e apenas a altura é influenciada pela espécie (Tabela 2).

Tabela 1. Médias de altura (H), diâmetro (D), área foliar (AF) e massa seca do sistema radicular (MSSR) de mudas de eucaliptos produzidas em recipientes de diferentes volumes aos 120 dias após a semeadura.

\begin{tabular}{lccc}
\hline \multirow{2}{*}{ Variáveis } & \multicolumn{2}{c}{ Recipientes } & \multirow{2}{*}{$\mathbf{C V}$} \\
\cline { 2 - 3 } & Tubetes $\mathbf{5 5} \mathbf{c m}^{\mathbf{3}}$ & $\begin{array}{c}\text { Tubetes } \\
\mathbf{1 8 0} \mathbf{~ c m}^{\mathbf{3}}\end{array}$ & $\mathbf{( \% )}$ \\
\hline $\mathrm{H}(\mathrm{cm})$ & $24,81 \mathrm{~b}$ & $54,17 \mathrm{a}$ & 9,25 \\
$\mathrm{D}(\mathrm{mm})$ & $3,17 \mathrm{~b}$ & $5,52 \mathrm{a}$ & 6,51 \\
$\mathrm{AF}\left(\mathrm{cm}^{2}\right)$ & $88,93 \mathrm{~b}$ & $273,83 \mathrm{a}$ & 17,39 \\
MSSR $(\mathrm{g})$ & $0,42 \mathrm{~b}$ & $1,20 \mathrm{a}$ & 19,28 \\
\hline
\end{tabular}

Médias seguidas pela mesma letra minúscula nas linhas, não diferem entre si pelo teste $\mathrm{F}$ da análise de variância a $5 \%$. CV(\%) = Coeficiente de variação.

Tabela 2. Médias de altura (H), diâmetro (D), área foliar (AF) e massa seca do sistema radicular (MSSR) de mudas de dife$\underline{\text { rentes espécies de eucalipto aos } 120 \text { dias após a semeadura. }}$

\begin{tabular}{ccccc}
\hline \multirow{2}{*}{ Variáveis } & \multicolumn{3}{c}{ Espécies } & CV \\
\cline { 2 - 4 } & $\begin{array}{c}\text { Eucalyptus } \\
\text { urophylla }\end{array}$ & $\begin{array}{c}\text { Eucalyptus } \\
\text { robusta }\end{array}$ & $\begin{array}{c}\text { Corymbia } \\
\text { citriodora }\end{array}$ & $(\%)$ \\
\hline $\mathrm{H}(\mathrm{cm})$ & $39,09 \mathrm{~b}$ & $44,35 \mathrm{a}$ & $35,03 \mathrm{~b}$ & 4,66 \\
$\mathrm{D}(\mathrm{mm})$ & $4,30 \mathrm{a}$ & $4,18 \mathrm{a}$ & $4,54 \mathrm{a}$ & 6,51 \\
$\mathrm{AF}\left(\mathrm{cm}^{2}\right)$ & $146,98 \mathrm{a}$ & $174,06 \mathrm{a}$ & $169,09 \mathrm{a}$ & 17,39 \\
$\mathrm{MSSR}(\mathrm{g})$ & $0,76 \mathrm{a}$ & $0,82 \mathrm{a}$ & $0,86 \mathrm{a}$ & 19,28 \\
\hline
\end{tabular}

Médias seguidas pela mesma letra minúscula nas linhas, não diferem entre si pelo teste de Tukey a 5\% . CV $(\%)=$ Coeficiente de variação.

Pode-se observar na Tabela 1 que as mudas produzidas em tubetes de $180 \mathrm{~cm}^{3}$ apresentaram o dobro de ganho em altura e MSSR e mais de $74 \%$ para diâmetro em relação às mudas que foram produzidas em tubetes de $55 \mathrm{~cm}^{3}$. O mesmo comportamento foi observado por 
José et al. (2005) para as mesmas variáveis quando trabalharam com Schinus terebinthifolia, em que as mudas produzidas em menor volume sofreram com a restrição causada pelo recipiente.

A área foliar foi uma das variáveis mais afetadas pelos sistemas de produção testados (Tabela 1). Mudas produzidas em tubetes de $180 \mathrm{~cm}^{3}$, no final do ciclo de produção, atingiram três vezes mais área foliar em relação às mudas produzidas em tubetes de $55 \mathrm{~cm}^{3}$. Resultados semelhantes foram relatados por Freitas et al. (2006) quando compararam recipientes de diferentes volumes, indicando que a restrição do sistema radicular das mudas de eucaliptos afeta diretamente a produção de área foliar.

Reis et al. (1989), trabalhando com E. grandis e $E$. cloeziana, demonstraram que as diferentes dimensões dos recipientes influenciam o crescimento dessas espécies, sendo as menores dimensões obtidas em mudas produzidas em recipientes de menor volume, o que eles atribuem à restrição das raízes. $\mathrm{O}$ uso de recipiente de maior volume permite que o sistema radicular da muda tenha maior espaço para o desenvolvimento e exploração do substrato, permitindo assim maior absorção de água e nutrientes pelas raízes, o que influencia de forma direta o crescimento das mudas em altura e diâmetro.

Foi observada diferença entre espécies apenas em altura (Tabela 2). Apesar do E. robusta ter apresentado maior altura em relação às outras espécies, todas apresentaram crescimento mínimo superior ao exigido como padrão de qualidade de mudas (Carneiro, 1995).

Os fatores tamanho de tubetes e espécies atuaram conjuntamente nas variáveis massa seca da parte aérea (MSPA) e número de folhas (NF). As mudas de todas as espécies apresentaram maior desenvolvimento quando utilizado recipientes de $180 \mathrm{~cm}^{3}$, aumentando de 2,6 a 5,2 vezes a MSPA, e de 1,4 a 3,5 vezes o NF em relação aos tubetes de $55 \mathrm{~cm}^{3}$ (Tabela 3 ).
Observa-se que não houve diferença entre as espécies nos tubetes de $55 \mathrm{~cm}^{3}$ para NF e MSPA (Tabela 3). O mesmo não foi observado quando se utilizou tubetes de $180 \mathrm{~cm}^{3}$, em que as mudas de E. urophylla apresentaram maior ganho de biomassa seca da parte aérea e maior número de folhas em relação às outras duas espécies. De acordo com Gomes \& Paiva (2011) o peso da matéria seca da parte aérea e do sistema radicular indica a rusticidade e correlaciona-se diretamente com a sobrevivência e desempenho inicial das mudas após o plantio no campo. Todas as espécies produzidas em tubetes de $180 \mathrm{~cm}^{3}$ apresentaram ganho de matéria seca da parte aérea e raiz, fator importante para a sobrevivência e desenvolvimento inicial após o plantio, principalmente em áreas que apresentam algum tipo de estresse como o déficit hídrico.

A análise estatística revelou não haver interação entre espécie e tamanho do tubete para as variáveis: número de raízes e percentagem de deformações radiculares (Figura 1).

Não foram observadas diferenças significativas quanto ao número de raízes entre as espécies. Os maiores valores de número de deformações e percentual de deformação foram apresentados pelas espécies $E$. urophylla e E. robusta. Mudas produzidas em tubetes de $180 \mathrm{~cm}^{3}$ apresentaram maior número de raízes $(19,6)$, entretanto não diferiram estatisticamente das plantas estabelecidas em tubetes de $55 \mathrm{~cm}^{3}$ quanto ao percentual de deformações.

$\mathrm{Na}$ Tabela 4 estão apresentados os incrementos médios em altura e diâmetro para as espécies estudadas no período de 120 dias. Todas as espécies obtiveram maior incremento em altura em tubetes de $180 \mathrm{~cm}^{3}$, sendo que o E. robusta apresentou as maiores médias para esta variável, nos dois tamanhos de tubetes testados.

Tabela 3. Médias do número de folhas (NF) e massa seca da parte aérea (MSPA) de mudas de eucalipto produzidas em recipientes de diferentes volumes, 120 dias após a semeadura.

\begin{tabular}{|c|c|c|c|c|}
\hline \multirow{2}{*}{ Espécie } & \multicolumn{2}{|c|}{ NF } & \multicolumn{2}{|c|}{ MSPA (g) } \\
\hline & Tubete $55 \mathrm{~cm}^{3}$ & Tubete $180 \mathrm{~cm}^{3}$ & Tubete $55 \mathrm{~cm}^{3}$ & Tubete $180 \mathrm{~cm}^{3}$ \\
\hline Eucalyptus urophylla & $9,56 \mathrm{~b} \mathrm{~A}^{1}$ & 33,25 a A & $0,94 \mathrm{~b} \mathrm{~A}$ & 4,91 a $\mathrm{A}$ \\
\hline Eucalyptus robusta & $11,69 \mathrm{~b} \mathrm{~A}$ & 20,94 a B & $1,10 \mathrm{~b} \mathrm{~A}$ & 3,74 a B \\
\hline Corymbia citriodora & 11,00 a $\mathrm{A}$ & 14,94 a B & $1,61 \mathrm{~b} \mathrm{~A}$ & 4,29 a $B$ \\
\hline $\mathrm{CV}(\%)$ & \multicolumn{2}{|c|}{20,55} & \multicolumn{2}{|c|}{16,84} \\
\hline
\end{tabular}

Médias seguidas pela mesma letra minúscula na linha e maiúscula na coluna dentro de uma mesma característica avaliada, não diferem entre si pelo teste de Tukey a $5 \%$. CV $(\%)=$ Coeficiente de variação. 

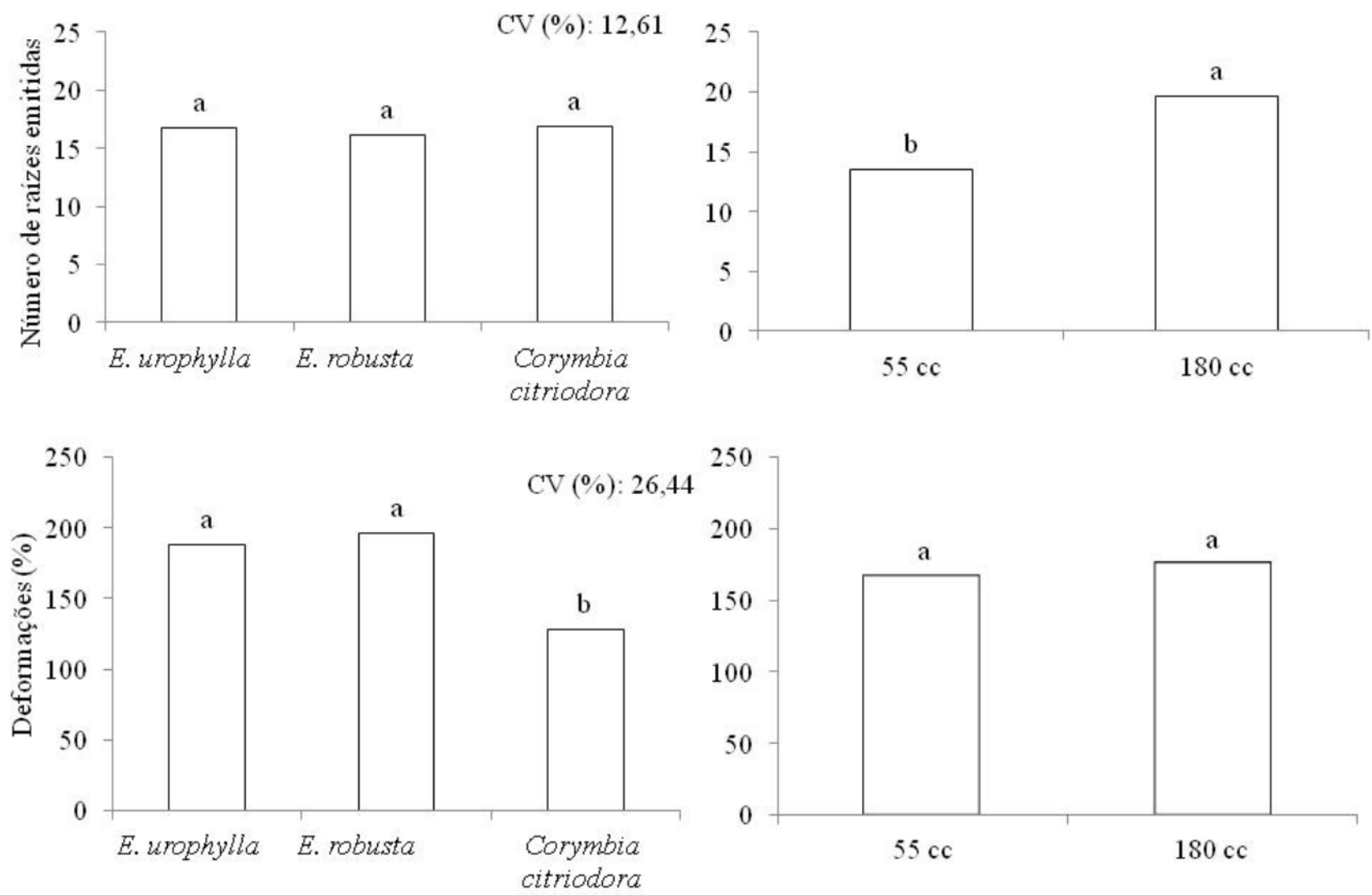

Figura 1. Médias do número de raízes e percentagem de deformações radiculares de mudas de Eucalyptus urophylla, E. robusta e Corymbia citriodora produzidas em dois tamanhos de tubete aos 120 dias após a semeadura. Médias seguidas por letras iguais não diferem estatisticamente.

Tabela 4. Incremento médio diário em altura (H) e diâmetro (D) de mudas de Eucalyptus urophylla, Eucalyptus robusta e Corymbia citriodora produzidas em dois tamanhos de tubete, analisadas por 120 dias.

\begin{tabular}{|c|c|c|c|c|}
\hline \multirow[b]{2}{*}{ Espécie } & \multicolumn{2}{|c|}{ Altura (cm) } & \multicolumn{2}{|c|}{ Diâmetro (mm) } \\
\hline & $55 \mathrm{~cm}^{3}$ & $180 \mathrm{~cm}^{3}$ & $55 \mathrm{~cm}^{3}$ & $180 \mathrm{~cm}^{3}$ \\
\hline Eucalyptus urophylla & 0,19 b B & 0,58 a B & $0,0196 \mathrm{~b} \mathrm{~A}$ & 0,0380 a $\mathrm{A}$ \\
\hline Eucalyptus robusta & $0,27 \mathrm{~b} \mathrm{~A}$ & 0,62 a $A$ & $0,0201 \mathrm{~b} \mathrm{~A}$ & 0,0357 a B \\
\hline Corymbia citriodora & $0,15 \mathrm{~b} \mathrm{C}$ & 0,51 a $\mathrm{C}$ & $0,0209 \mathrm{~b} \mathrm{~A}$ & 0,0364 a B \\
\hline $\mathrm{CV} \%$ & \multicolumn{2}{|c|}{4,9} & \multicolumn{2}{|c|}{6,1} \\
\hline
\end{tabular}

Médias seguidas por letras iguais minúsculas nas linhas e maiúsculas nas colunas não diferem estatisticamente. CV(\%)= Coeficiente de variação.

Nos tubetes de $55 \mathrm{~cm}^{3}$ o incremento em altura para $E$. urophylla e E. robusta é representado por uma equação do terceiro grau. Para a espécie E. urophylla o incremento máximo em altura ocorre aos 62 dias (Ponto de máximo); a partir deste momento o ritmo de crescimento diminui. A espécie E. robusta atingiu o incremento máximo em altura aos 60 dias, e o incremento em altura da espécie
C. citriodora é melhor representado por uma equação de segundo grau, com máximo incremento aos 75 dias (Figura 2). Lopes (2005), trabalhando com três espécies de Eucalyptus, observou o mesmo comportamento para o C. citriodora, onde a espécie apresentou menor ritmo de crescimento em altura para todos os recipientes utilizados quando foram levadas para o campo. 

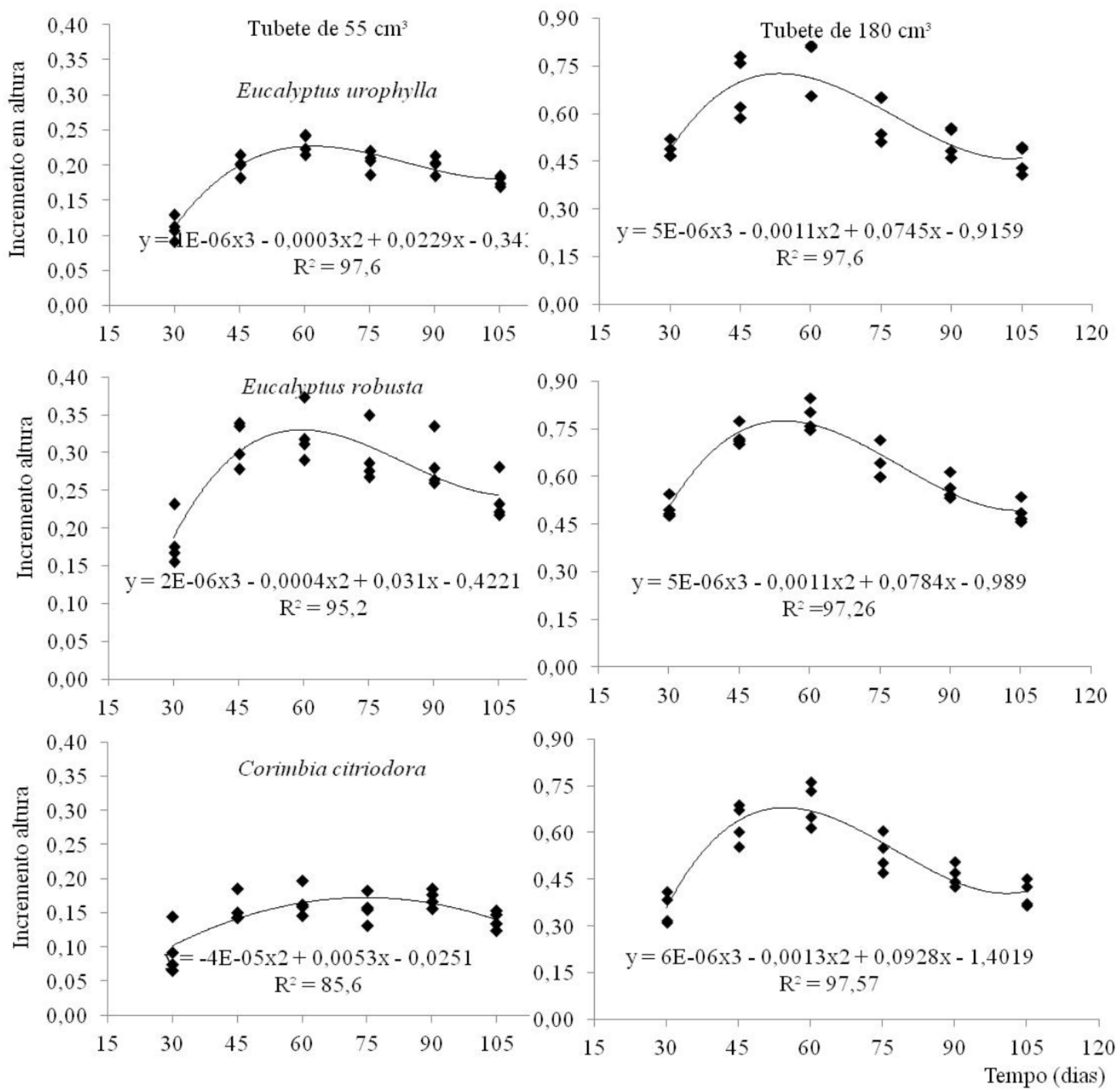

Figura 2. Incremento em altura (cm) de mudas de Eucalyptus urophylla, Eucalyptus robusta e Corymbia citriodora produzidas em dois tamanhos de tubete.

Nos tubetes de $180 \mathrm{~cm}^{3}$, os incrementos em altura das três espécies são representados por equações de terceiro grau (Figura 2). Ressalta-se que as três espécies atingem o ponto de máximo incremento mais precocemente em relação ao tubete de $55 \mathrm{~cm}^{3}$. Para a espécie E. urophylla este ponto de máximo ocorre aos 53 dias e para as espécies E. robusta e C.citriodora aos 55 dias.

Mafia et al. (2005) recomendam que mudas de $E$. grandis $\mathrm{x} E$. urophylla sejam levadas para o campo com
80 e 100 dias para evitar a redução da velocidade de crescimento e mal formação de raízes. De acordo com os resultados obtidos neste estudo, mudas provenientes de tubetes de $180 \mathrm{~cm}^{3}$ estão aptas para o plantio por volta de 55 dias, considerando a altura padrão recomendada de 15 a $25 \mathrm{~cm}$ (Carneiro 1995), havendo uma redução de pelo menos 25 dias no ciclo de produção de mudas, considerando a recomendação de Mafia et al. (2005). No entanto, antes de serem levadas para o campo é necessário o processo de rustificação. 
Com relação aos incrementos e diâmetro, as espécies estudadas também apresentaram os maiores valores médios em tubetes de $180 \mathrm{~cm}^{3}$ (Tabela 4). Analisando os resultados em tubetes de $55 \mathrm{~cm}^{3}$, constatou-se não haver diferença significativa para esta variável entre as espécies, enquanto que em recipientes de $180 \mathrm{~cm}^{3}$ a espécie E. urophylla apresentou o maior incremento médio diário (Tabela 4).
Para as três espécies, nos dois tamanhos de tubetes, ajustaram-se equações de segundo grau para representar a tendência de crescimento em diâmetro em função do tempo (Figura 3), diante das quais constatou-se que o máximo incremento para todas as espécies e tamanhos de tubetes ocorreu entre 73 e 76 dias, exceto para o $C$. citriodora no tubete de $180 \mathrm{~cm}^{3}$, que atingiu o máximo incremento aos 83 dias (Figura 3).
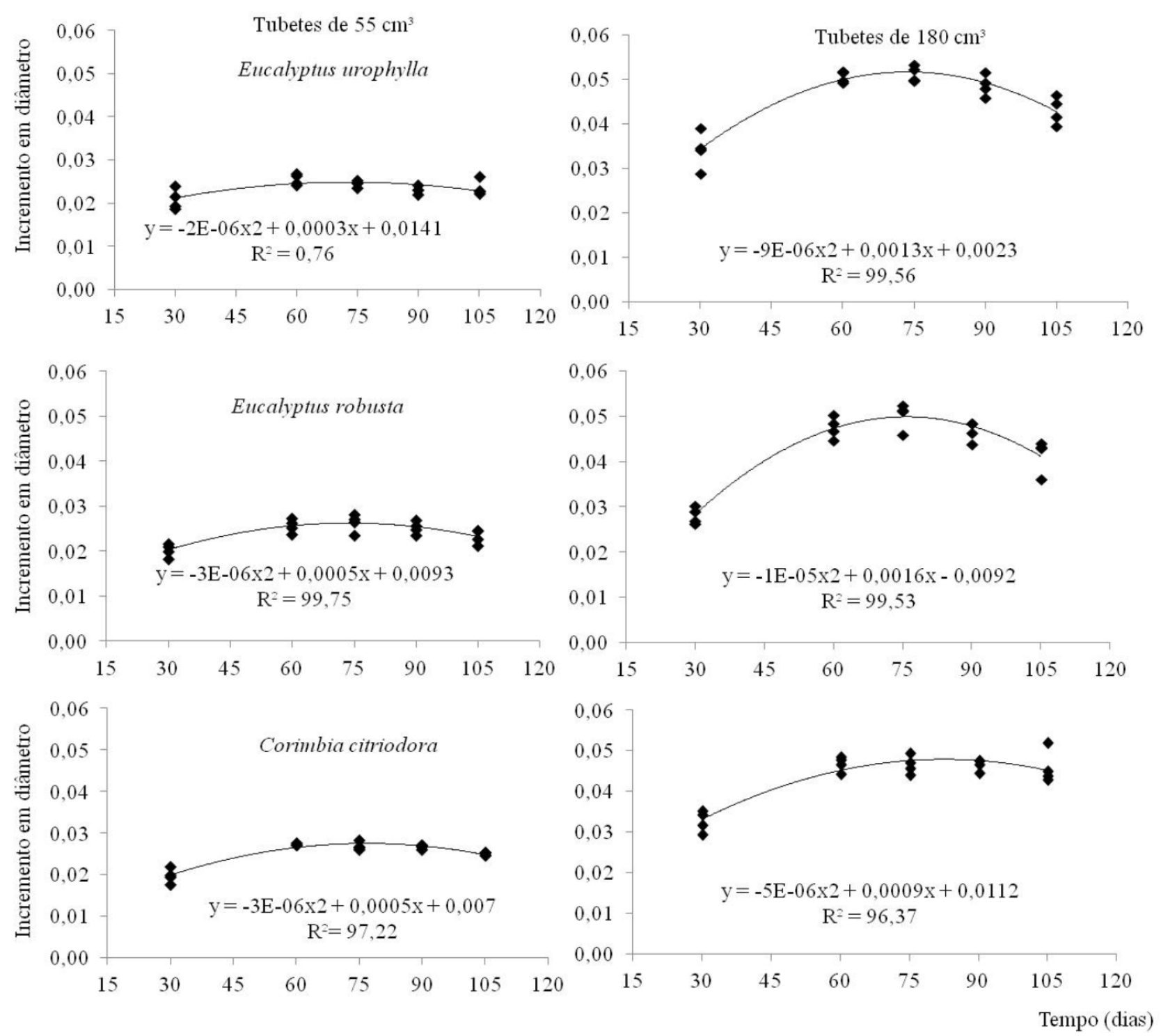

Figura 3. Incremento em diâmetro $(\mathrm{mm})$ de mudas de Eucalyptus urophylla, Eucalyptus robusta e Corymbia citriodora produzidas em dois tamanhos de tubete. 
De acordo com Carneiro (1995), mudas de eucalipto para serem levadas para o campo devem apresentar o diâmetro de colo mínimo de $2,5 \mathrm{~mm}$ e sua altura deve estar entre 15 e $25 \mathrm{~cm}$. Em contrapartida, para Gomes et al. (2002), pode-se adotar apenas a altura para estimar a qualidade das mudas. Para as condições desse trabalho, esses valores foram atingidos por volta de 60 dias após o semeio para o diâmetro e por volta de 55 dias para altura quando as mudas foram produzidas em tubetes de $180 \mathrm{~cm}^{3}$. Quando produzidas em recipientes de 55 $\mathrm{cm}^{3}$, as mudas atingiram o padrão mínimo exigido aos 120 dias após a semeadura (Figura 4).
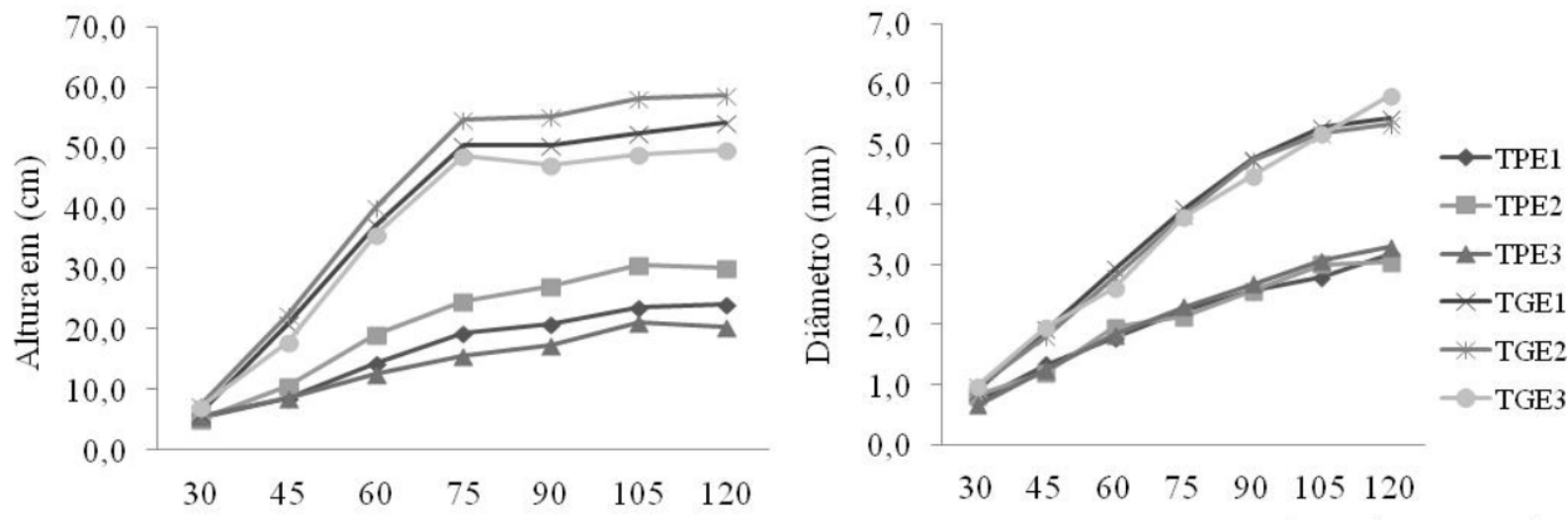

Dias após a Semeadura

Figura 4. Altura e diâmetro da parte aérea de mudas de eucalipto, produzidas em dois tamanhos de recipientes. TPE1 = Tubete de $55 \mathrm{~cm}^{3}$ com Eucalyptus urophylla; TPE2 = Tubete de $55 \mathrm{~cm}^{3}$ com Eucalyptus robusta; TPE3 = Tubete de $55 \mathrm{~cm}^{3} \mathrm{com}$ Corymbia citriodora; TGE1 = Tubete de $180 \mathrm{~cm}^{3}$ com Eucalyptus urophylla; TGE2 = Tubete de $180 \mathrm{~cm}^{3} \mathrm{com}$ Eucalyptus robusta; TGE3 $=$ Tubete de $180 \mathrm{~cm}^{3}$ com Corymbia citriodora .

O ritmo de crescimento, expresso pelo incremento, determina o período de permanência da muda no viveiro. Segundo Cunha et al. (2005), trabalhando com mudas de Tabebuia impetiginosa, os recipientes menores tendem a reduzir a taxa de crescimento e aumentar o ciclo de produção das mudas. Ferraz \& Engel (2011), comparando valores de altura e diâmetro de mudas de espécies florestais nativas produzidas em tubetes de 50 e $300 \mathrm{~cm}^{3}$, demonstraram que pode haver uma redução do ciclo de produção das mudas em até 70 dias quando estas são produzidas no recipiente de maior volume.

$O$ recipiente de $55 \mathrm{~cm}^{3}$ tem sido o mais utilizado na produção de mudas de eucaliptos. Entretanto, os resultados apontam que recipiente de volume reduzido limita o desenvolvimento das espécies testadas em todas as características avaliadas, devendo as empresas de produção de mudas de eucalipto analisar o uso de um recipiente de maior volume, o que poderá resultar na redução do ciclo de produção em $50 \%$. Sendo assim, considerando bandejas de $2.400 \mathrm{~cm}^{2}$, as quais tem capacidade para 48 mudas, na fase final de produção, para tubetes de $55 \mathrm{~cm}^{3}$ e de 27 para tubetes de $180 \mathrm{~cm}^{3}$, ao final de quatro meses a utilização de tubetes maiores resultará na produção de seis mudas a mais em relação a utilização de tubetes menores, por bandeja.

A espécie e o tamanho do tubete atuam de forma independente em todas as variáveis avaliadas após dois meses do transplantio para as sacolas. Mudas produzidas nos tubetes de $55 \mathrm{~cm}^{3}$ aos dois meses apresentaram menor crescimento em altura e diâmetro, menores massa seca da parte aérea e raiz e maior número de deformações de raízes, independente da espécie avaliada (Tabela 5). Barroso et al. (2000b) também observaram comportamento semelhante quando produziram mudas de eucaliptos em recipientes de diferentes volumes, onde as mudas produzidas em recipientes que comportavam maior volume de substrato apresentaram maior desenvolvimento até dez meses após plantio no campo em relação as mudas produzidas no menor recipiente.

De acordo com Freitas et al. (2006) a restrição das mudas no viveiro em função do volume do recipiente utilizado para a sua produção pode reduzir ou atrasar o crescimento das plantas no campo acarretando maiores gastos com controle de plantas daninhas e retardamento da produção esperada. 
Tabela 5. Médias de altura (H), diâmetro (D), massa seca da parte aérea (MSPA), massa seca do sistema radicular (MSSR) e número de raízes (NR), número de deformações (ND) e percentagem de deformações (\%DF) dois meses após o transplantio.

\begin{tabular}{cccccccc}
\hline Tubetes & H $(\mathbf{c m})$ & $\mathbf{D}(\mathbf{m m})$ & MSPA $(\mathbf{g})$ & MSSR $(\mathbf{g})$ & NR & ND & \%DF \\
\hline $55 \mathrm{~cm}^{3}$ & $87,74 \mathrm{~b}$ & $8,34 \mathrm{~b}$ & $23,12 \mathrm{~b}$ & $6,23 \mathrm{~b}$ & $19,79 \mathrm{a}$ & $27,88 \mathrm{~b}$ & $165,41 \mathrm{~b}$ \\
$180 \mathrm{~cm}^{3}$ & $95,46 \mathrm{a}$ & $10,27 \mathrm{a}$ & $29,33 \mathrm{a}$ & $8,53 \mathrm{a}$ & $23,42 \mathrm{a}$ & $39,83 \mathrm{a}$ & $162,71 \mathrm{a}$ \\
$\mathrm{CV}(\%)$ & 9,45 & 7,40 & 19,97 & 31,04 & 28,99 & 28,88 & 25,05 \\
\hline
\end{tabular}

Médias seguidas por letras iguais nas colunas não diferem estatisticamente pelo teste F/Anova a 5\% de probabilidade. CV(\%)=Coeficiente de variação.

Não houve diferença para o número de raízes, número de deformações e percentagem de deformações entre as espécies estudadas (Tabela 6). E. robusta apresentou maior produção de massa seca da parte aérea (MSPA) e massa seca do sistema radicular (MSSR), e maior crescimento em altura e diâmetro em relação às outras espécies, não se diferenciando do E. urophylla para produção de MSSR e crescimento em diâmetro.
O volume dos tubetes e as espécies atuam independentemente no incremento em altura e diâmetro no período de dois meses de simulação de campo. As espécies não diferem com relação ao incremento em altura, mas o incremento em diâmetro é menor em $C$. citriodora (Tabela 7). $\mathrm{O}$ volume do tubete não afeta $\mathrm{o}$ incremento em diâmetro, embora o incremento em altura tenha sido superior no tubete de menor volume (Tabela 8).

Tabela 6. Médias de altura (H), diâmetro (D), massa seca da parte aérea (MSPA), massa seca do sistema radicular (MSSR) e número de raízes (NR), número de deformações (ND) e percentagem de deformações (\%DF) de mudas de Eucalyptus urophylla, Eucalyptus robusta e Corymbia citriodora, dois meses após o transplantio.

\begin{tabular}{lccccccc}
\hline \multicolumn{1}{c}{ Espécie } & H $(\mathbf{c m})$ & D $(\mathbf{m m})$ & MSPA $(\mathbf{g})$ & MSSR $(\mathbf{g})$ & NR & N D & \%DF \\
\hline E. urophylla & $84,31 \mathrm{~b}$ & $9,69 \mathrm{a}$ & $25,92 \mathrm{~b}$ & $6,93 \mathrm{ab}$ & $22,69 \mathrm{a}$ & $37,00 \mathrm{a}$ & $156,74 \mathrm{a}$ \\
E. robusta & $101,48 \mathrm{a}$ & $9,91 \mathrm{a}$ & $32,76 \mathrm{a}$ & $9,13 \mathrm{a}$ & $24,44 \mathrm{a}$ & $35,88 \mathrm{a}$ & $170,41 \mathrm{a}$ \\
C. citriodora & $89,02 \mathrm{~b}$ & $8,31 \mathrm{~b}$ & $19,99 \mathrm{~b}$ & $6,08 \mathrm{~b}$ & $17,69 \mathrm{a}$ & $28,69 \mathrm{a}$ & $165,03 \mathrm{a}$ \\
\hline CV $(\%)^{1}$ & 9,45 & 7,40 & 19,97 & 31,04 & 28,99 & 28,88 & 25,05 \\
\hline
\end{tabular}

Médias seguidas por letras iguais minúsculas nas colunas não diferem estatisticamente pelo teste Tukey a $5 \%$ de probabilidade dentro de uma mesma variável. $\mathrm{CV}(\%)=$ Coeficiente de variação.

Tabela 7. Incremento em altura (H) e diâmetro (D) de mudas de eucaliptos dois meses após o transplantio para sacolas.

\begin{tabular}{lcc}
\hline \multicolumn{1}{c}{ Espécie } & H $(\mathbf{c m})$ & D $(\mathbf{m m})$ \\
\hline Eucalyptus urophylla & $48,09 \mathrm{a}$ & $5,30 \mathrm{a}$ \\
Eucalyptus robusta & $54,95 \mathrm{a}$ & $5,61 \mathrm{a}$ \\
Corymbia citriodora & $52,53 \mathrm{a}$ & $3,67 \mathrm{~b}$ \\
\hline CV $(\%)$ & 16,88 & 12,26 \\
\hline
\end{tabular}

Médias seguidas por letras iguais nas colunas não diferem estatisticamente pelo teste Tukey a $5 \%$ de probabilidade. CV $(\%)=$ Coeficiente de variação.

Tabela 8. Incremento em altura (H) e diâmetro (D) de mudas de eucaliptos produzidas em tubetes com diferentes volumes, dois meses após o transplantio para sacolas.

\begin{tabular}{ccc}
\hline Tubete & Incremento $\mathbf{H}(\mathbf{c m})$ & Incremento D $\mathbf{( m m})$ \\
\hline $55 \mathrm{~cm}^{3}$ & $61,44 \mathrm{a}$ & $4,94 \mathrm{a}$ \\
$180 \mathrm{~cm}^{3}$ & $42,28 \mathrm{~b}$ & $4,79 \mathrm{a}$ \\
\hline $\mathrm{CV}(\%)$ & 16,88 & 12,26 \\
\hline
\end{tabular}

Médias seguidas por letras iguais nas colunas não diferem estatisticamente pelo teste F/Anova a $5 \%$ de probabilidade. CV(\%) $=$ Coeficiente de variação. 
As mudas provenientes dos tubetes de $55 \mathrm{~cm}^{3}$, que sofreram restrição durante a fase de produção de mudas, tendem a recuperar o crescimento no campo após o plantio. No entanto, esses resultados mostram que o efeito da restrição radicular causada pelo recipiente de menor volume afeta o crescimento inicial em altura das mudas após o transplantio para sacolas. O mesmo comportamento foi observado por Freitas et al. (2005).

\section{Conclusões}

As mudas das espécies de eucalipto avaliadas produzidas em tubetes de $180 \mathrm{~cm}^{3}$ apresentaram maior crescimento para todas as variáveis avaliadas, podendo ser levadas para o campo em torno de 60 dias, diminuindo o seu ciclo de produção no viveiro, em comparação aos tubetes menores $\left(55 \mathrm{~cm}^{3}\right)$, cujo ciclo é de 120 dias.

\section{Referências}

BARROSO, D. G.; CARNEIRO, J. G. de A.; NOVAES, A. B. de; LELES, P. S. dos S. Efeitos do recipiente sobre o desempenho pósplantio de Eucalyptus camaldulensis Dehnh. e E. urophyla S. T. Blake. Revista Árvore, Viçosa, MG, v. 24, n. 32, p. 291-296, 2000a

BARROSO, D. G.; CARNEIRO, J. G. A.; LELES, P. S. S. Qualidade de mudas de Eucalyptus camaldulensis e E. urophylla produzidas em tubetes e em blocos prensados, com diferentes substratos. Floresta e Ambiente, Soropédica, v. 7, n. 1, p. 238-250, 2000 b.

CARNEIRO, J. G. A. Produção e controle de qualidade de mudas florestais. Curitiba: UFPR/FUPEF; Campos: UENF, 1995. 451 p.

CONSTANTINO, V. et al. Efeitos de métodos de produção de mudas e equipes de plantadores no crescimento de Pinus taeda Linnaeus. Scientia Forestalis, Piracicaba, v. 38, n. 87, p. 355-366, 2010.

CUNHA, A. O. et al. Efeitos de substratos e das dimensões dos recipientes na qualidade das mudas de Tabebuia impetiginosa (Mart. Ex D.C.) Standl. Revista Árvore, Viçosa, MG, v. 29, n. 4, p. 507-516, 2005.

DIAS, L. A. S.; BARROS, W. S. Biometria experimental. Viçosa, MG: Suprema Gráfica, 2009. 408 p.

FERRAZ, A. V.; ENGEL, V. L. Efeito do tamanho de tubetes na qualidade de mudas de jatobá (Hymenaea courbaril L. VAR. stilbocarpa (Hayne) Lee Et Lang.), ipê-amarelo (Tabebuia chrysotricha (Mart. ex DC.) Sandl.) e guarucaia (Parapiptadenia rigida (Benth.) Brenan). Revista Árvore, Viçosa, MG, v. 35, n. 3, p. 413-423, 2011.

FREITAS, T. A. S. et al. Mudas de eucalipto produzidas a partir de miniestacas em diferentes recipientes e substratos. Revista Árvore, Viçosa, MG, v. 30, n. 4, p. 519-528, 2006.

FREITAS, T. A. S. et al. Desempenho radicular de mudas de eucalipto produzidas em diferentes recipientes e substratos. Revista Árvore, Viçosa, MG, v. 29, n. 6, p. 853-861, 2005.
FREITAS, T. A. S. et al. Efeito de deformação e poda das raízes de mudas de eucalipto sobre o crescimento no campo. Floresta, Curitiba, v. 39, n. 2, p. 355-363, 2009.

GOMES, J. M. et al. Parâmetros morfológicos na avaliação da qualidade de mudas de Eucalyptus grandis. Revista Árvore, Viçosa, MG, v. 26, n. 6, p. 655-664, 2002.

GOMES, J. M.; PAIVA, H. N. Viveiros florestais: propagação sexuada. 3. ed. Viçosa, MG: UFV, 2006. 116 p.

GOMES, J. M.; PAIVA, H. N. Viveiros florestais: propagação sexuada. Viçosa, MG: UFV, 2011. 116 p. (Série Didática).

HIGA, A. R.; HIGA, R. C. V. Indicação de espécies para reflorestamento. In: GALVÃO, A. P. M. (Org.) Reflorestamento de propriedades rurais para fins produtivos e ambientais: um guia para ações municipais e regionais. Brasília, DF: Embrapa Informação Tecnológica; Colombo: Embrapa Florestas, 2000. p. 101-124.

JOSÉ, A. C.; DAVIDE, A. C.; OLIVEIRA, S. L. de. Produção de mudas de aroeira (Schinus terebinthifolius Raddi) para recuperação de áreas degradadas pela mineração de bauxita. Cerne, Lavras, v. 11, n. 2, p. 187-196, 2005.

LELES, P. S. S. et al. Crescimento e arquitetura radicial de plantas de eucalipto oriundas de mudas produzidas em blocos prensados e em tubetes, após o plantio. Cerne, Lavras, v. 7, n. 1, p. 10-19, 2001.

LESSA, L. S. et al. Avaliação agronômica em híbridos diplóides (AA) de bananeira. Ciência e Agrotecnologia, Lavras, v. 33, número especial, p. 1716-1721, 2009.

LOPES, E. D. Qualidade de mudas de Eucalyptus urophylla, E. camaldulensis e $E$. citriodora produzidas em blocos prensados e em dois modelos de tubetes e seu desempenho em campo. 2005. 82 f. Dissertação (Mestrado em Agronomia) - Universidade Estadual do Sudoeste da Bahia, Vitória da Conquista.

MAFIA, R. G. et al. Critério técnico para determinação da idade ótima de mudas de eucalipto para plantio. Revista Árvore, Viçosa, MG, v. 29, n. 6, p. 947-953, 2005.

MENDONÇA, A. V. R. et al. Características fisiológicas de mudas de Eucalyptus spp submetidas a estresse salino. Ciência Florestal, Santa Maria, RS, v. 20, n. 2, p. 255-267, 2010.

MORA, A. L.; GARCIA, C. H. A cultura do eucalipto no Brasil. São Paulo: Sociedade Brasileira de Silvicultura, 2000. 114 p.

REIFF, E. T. Eucalipto Citriodora: uma nova opção aos produtores rurais. Informativo Agropecuário Coopercitrus, Bebedouro, ano 22, n. 273, 2009.

REIS, G. G. et al. Crescimento de Eucalyptus camaldulensis, E. grandis e E. cloeziana sob diferentes níveis de restrição radicular. Revista Árvore, Viçosa, MG, v. 13, n. 1, p. 1-18, 1989.

SCANAVACA JUNIOR, L.; GARCIA, J. N. Potencial de melhoramento genético em Eucalyptus urophylla procedente da Ilha Flores. Scientia Forestalis, Piracicaba, n. 64, p. 23-32, 2003.

SUPERINTENDÊNCIA DE ESTUDOS ECONÔMICOS E SOCIAIS DA BAHIA. Estatística dos municípios baianos. Salvador, 2010. v. 13. 382 p.

VIANA, J. S. et al. Crescimento de mudas de Bauhinia forficata Link. em diferentes tamanhos de recipientes. Floresta, Curitiba, v. 38, n. 4, p. 663-671, 2008. 